\title{
A familial disorder associated with palatal myoclonus, other brainstem signs, tetraparesis, ataxia and Rosenthal fibre formation
}

\author{
R S Howard, R Greenwood, J Gawler, F Scaravilli, C D Marsden, A E Harding
}

Department of

Neurology, St.

Bartholomew's

Hospital, London

R S Howard ${ }^{\star}$

R Greenwood

J Gawler

The National Hospital

for Neurology and

Neurosurgery, *

London

F Scaravilli

C D Marsden

A E Harding

Correspondence to

Dr Greenwood,

Department of Neurology,

St. Bartholomew's Hospital

West Smithfield, London

EC1A 7BE, UK

Received 27 July 1992

and in revised form

7 December 1992

Accepted 15 December 1992

\begin{abstract}
Three siblings presented with a progressive neurological disorder beginning in the third decade of life and characterised by palatal myoclonus, nystagmus, bulbar weakness and spastic tetraparesis. There was no evidence of intellectual deterioration or seizures. CT scan showed marked brainstem atrophy in two patients and basal ganglia calcification in one. MRI scan in one showed high signal in the brainstem and periventricular region and cerebral biopsy in this patient showed myelin loss and the presence of Rosenthal fibres. A similar disease affected the siblings' mother, maternal aunt and two of the aunt's daughters, suggesting an autosomal dominant mode of transmission of what appears to be a unique genetic disorder.
\end{abstract}

$(F$ Neurol Neurosurg Psychiatry 1993;56:977-981)

Symptomatic palatal myoclonus is characterised by rhythmic oscillations of the soft palate which may be associated with synchronous contractions of muscles derived from the branchial arches, including the diaphragm, tongue and sternomastoids. ${ }^{1-3}$ This movement disorder may occur in association with a variety of brainstem lesions including those resulting from trauma, neoplasm, cerebrovascular disease, encephalitis and demyelination. Branchial myoclonus has also been reported in association with degenerative ataxic disorders which may be sporadic $^{4-6}$ or

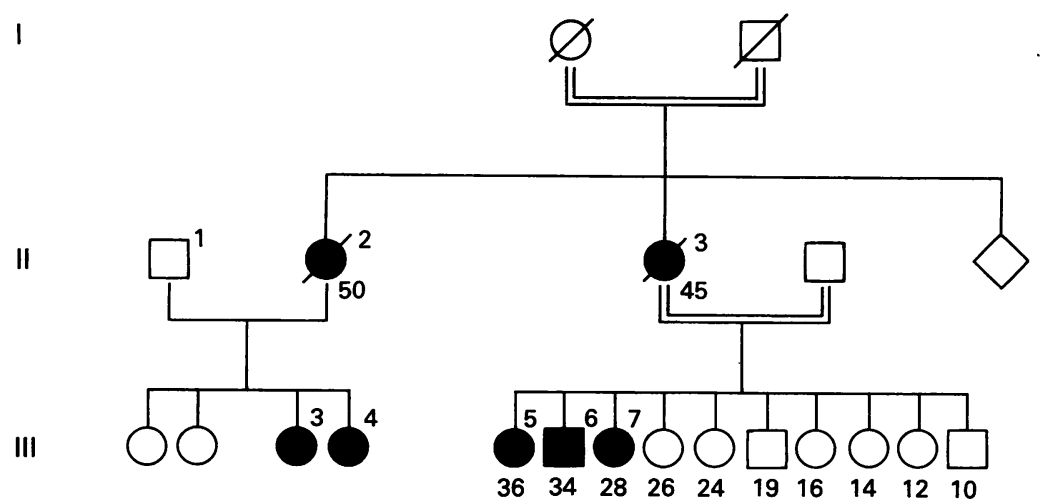

Figure 1 Family pedigree. Filled squares or circles represent affected members and open symbols represent asymptomatic individuals. Symbols crossed by a bar represent deceased individuals. Numbers underneath symbols indicate age or age at death. Double line shows consanguinous marriages.

familial $^{7}$ although there were no pathological findings reported in these cases. ${ }^{4-7}$

Rosenthal fibres are round or fusiform eosinophilic hyaline bodies which are the pathological hallmark of Alexander's disease in which they are present in all subpial, perivascular and subependymal regions throughout the cortex, white matter and spinal cord. They are composed of masses of intracellular astrocytic fibres. ${ }^{8-11}$ Rosenthal fibres are not unique to Alexander's disease and may be found in a variety of neurological disorders in which there is longstanding reactive gliosis. ${ }^{1012}$ These include intramedullary ependymomas associated with syringomyelia, ${ }^{8}$, astrocytoma, optic nerve glioma, craniopharyngioma, haemangioblastomas, gliomatosis, encephalomalacia, ${ }^{13}$ malignant melanoma, following vincristine or radiotherapy ${ }^{14}$ and complicating central pontine myelinolysis, prolonged sepsis, malnutrition and intravenous hyperalimentation. ${ }^{12} 15$

We report a family in which an autosomal dominant neurodegenerative disorder was characterised clinically by branchial myoclonus, bulbar palsy, nystagmus and spasticity, associated with Rosenthal fibres and myelin loss on cerebral biopsy.

\section{Case reports}

The index cases (III.5, 6 and 7) are the three eldest children of third cousin parents (fig 1). Their mother (II.3) developed a paraparesis in her late 30s and, following a myelogram, became tetraplegic. She subsequently developed speech and swallowing difficulties which culminated in death at the age of 45 . The maternal aunt (II.2) had a similar illness and was bed bound for 13 years before death in her 50s. Her two affected daughters (III.3, III.4) have similar symptoms to the index cases. The maternal grandparents were second cousins but were unaffected. The affected aunt and her husband were not consanguinous.

\section{Case III. 7}

A 25 year old Kuwaiti woman experienced three episodes of numbness affecting the right side of her face, neck and upper arm which recovered completely after several weeks. Two years later she slipped and landed heavily, hurting her lower back. She subsequently became aware of gradually worsening back pain and leg weakness and required increasing support to walk. She became completely 

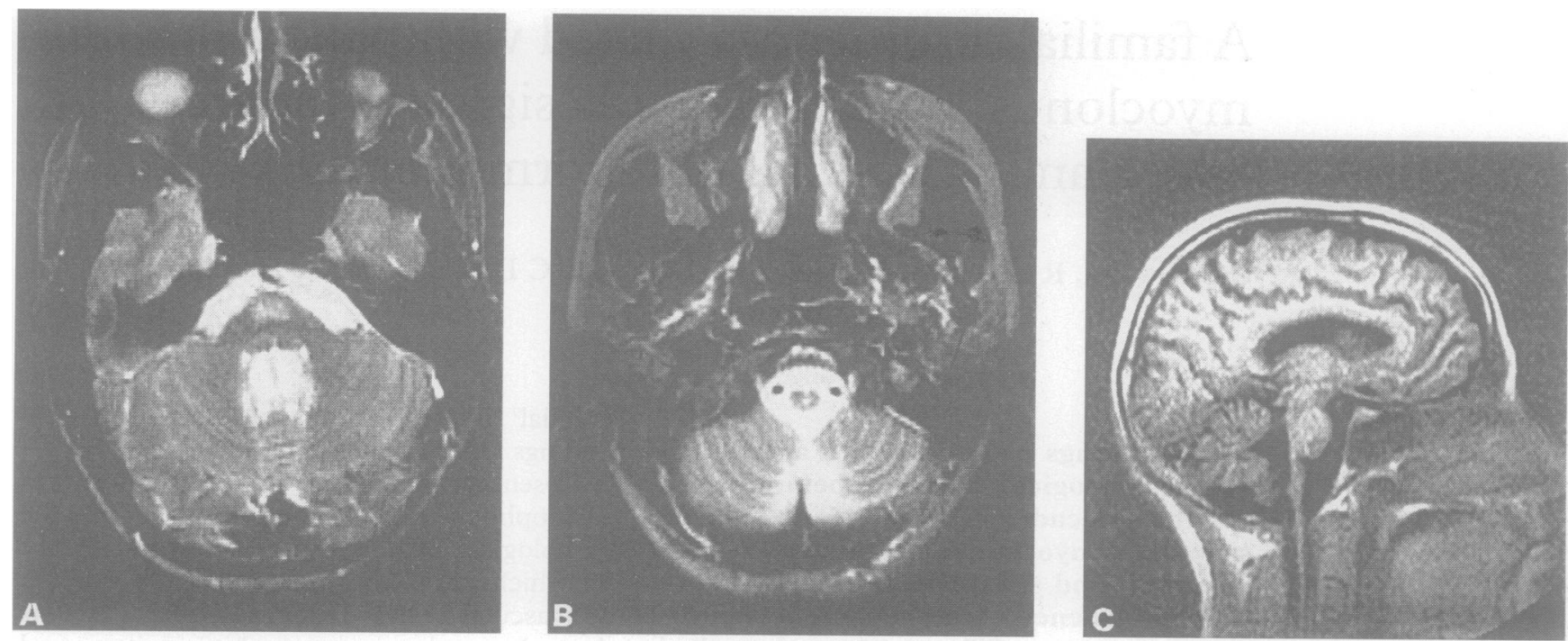

Figure 2 (A)

Unenhanced $T 2$ weighted axial MRI showing high signal returned from the brainstem. (Patient III.7); (B) Unenhanced T2 weighted axial MRI

showing marked atrophy of the medulla and cerebellum. (Patient III.7); (C) Unenhanced T1 weighted sagittal MRI showing marked atrophy of the brainstem and upper cervical cord. (Patient III.7). unable to walk six months later and developed difficulty turning in bed. She also complained of transient horizontal diplopia when changing her direction of gaze, a tremulous voice, difficulty initiating micturition and emptying her bladder and dysuria. Cognitive functions were normal and there was no dysphasia or dysarthria but her voice was tremulous. She could sit without support but required assistance to stand. Visual acuity, fields and fundi were normal but there was a bilateral internuclear ophthalmoplegia with broken up pursuit movements, horizontal and rebound nystagmus and reduced optokinetic nystagmus. There was palatal myoclonus and tongue fasciculations; the lower cranial nerves were otherwise normal. She had a spastic tetraparesis with mild weakness in the arms but severe weakness in the legs. There were no sensory or cerebellar signs.

The following investigations were negative or normal: full blood count, ESR, clotting studies, urea, electrolytes, glucose, liver and thyroid function, creatine kinase autoantibody screen, electrophoresis, treponemal serology, serum angiotensin converting enzyme, serum lactate and pyruvate, chest $x$ ray, ECG, viral and legionella, borrelia, brucella, mycoplasma and psittacosis serology, CSF cell count, protein, glucose, cytology, electrophoresis and serology. CT scan showed cortical atrophy with bilateral basal ganglia calcification. MRI of the head and spine showed abnormal signal in the subependymal white matter of all the ventricles. A large discrete lesion was present in the pons and abnormal signal was returned from the medulla and midbrain (fig $2 \mathrm{~A}$ ). The ventricles were large and there was marked atrophy of the medulla, cervical and upper dorsal cord (fig 2B, C). Peripheral nerve conduction studies, EMG and VEPs were normal but muscle biopsy was grossly abnormal showing changes of denervation atrophy with evidence of collateral reinnervation; there were no ragged red fibres. A CT directed stereotactic biopsy was performed (Professor DG Thomas) from periventricular white matter of the right frontal horn and from the pons. Histological examination showed small, patchy areas of pallor in the white matter which had irregular borders and in which axons were well preserved. No cuffing of the vessels with inflammatory cells was seen. Rosenthal fibres were irregularly scattered in the tissue, predominantly where there was myelin loss where they often formed small irregular clusters (fig 3). On occasions they surrounded small vessels. They were clubbed shaped or irregularly round, intensely eosinophilic and with jagged edges. No iron positive pigment was seen. Silver impregnation for axons showed no axonal swelling.

Over the next six months she continued to deteriorate physically with increasing limb weakness and breathlessness. She required an indwelling urinary catheter. Severe pyramidal weakness of the arms and a complete spastic paraplegia evolved. The respiratory pattern was regular but shallow with orthodox diaphragmatic excursion. Her vital capacity fell from 1.2 litres to 0.9 litres.

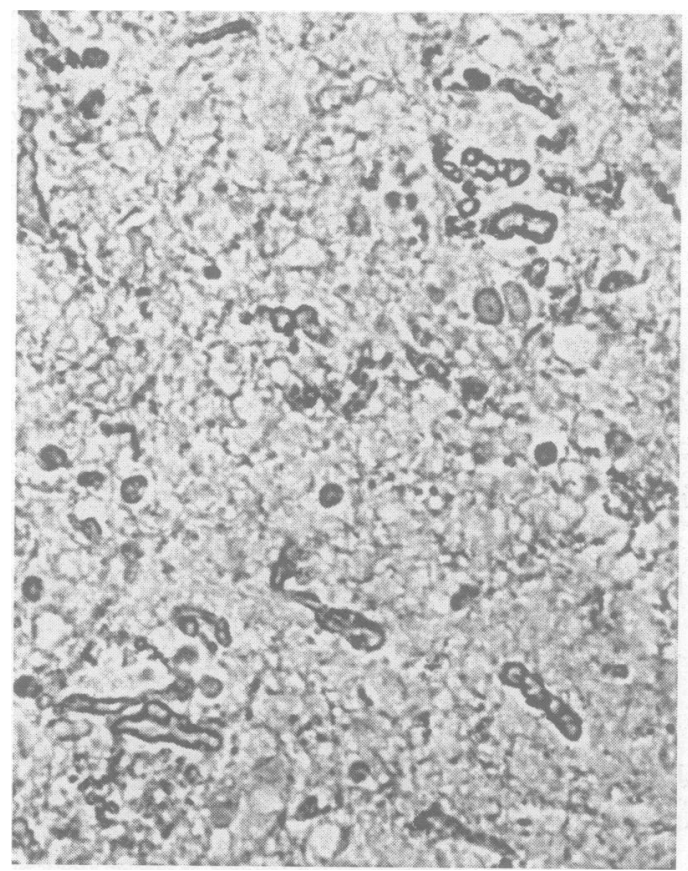

Figure 3 Photomicrograph of the cerebral biopsy (Patient III.7) showing Rosenthal fibres in a demyelinated area. $(G>F>A>P . \times 300)$ 


\section{Case III. 6}

This 27 year old man became increasingly aware of hoarseness, nocturnal stridor and a tendency to choke. An attack of laryngeal spasm led to the recognition of bilateral abductor paralysis of the vocal cords and a permanent tracheostomy was fashioned. Five years later he developed increasing headache, slurred speech, pain in his legs and back, weakness and numbness of the legs and progressive unsteadiness of gait. Sneezing was associated with attacks of paralysis involving his limbs. Cognitive functions were normal. On examination there was nasal dysarthria, horizontal nystagmus, complete vocal cord abductor paralysis, tongue fasciculations, a mild spastic tetraparesis and gait ataxia. Routine investigations including CSF examination were negative or normal. A CT scan suggested brainstem atrophy and a cervical myelogram showing striking atrophy of the spinal cord (fig 4). Over the following two years his balance and gait deteriorated and he became wheelchair bound. He continued to choke frequently. On examination there was horizontal nystagmus and myoclonus involving the palate, tongue and sternomastoids. Voluntary palatal power and tongue movements were normal. There had been progression of the tetraparesis with more marked distal upper limb weakness and worsening ataxia.

\section{Case III.5}

This 29 year old woman was well until 1984 when she developed episodes of giddiness and numbness of the left face and arm occur-

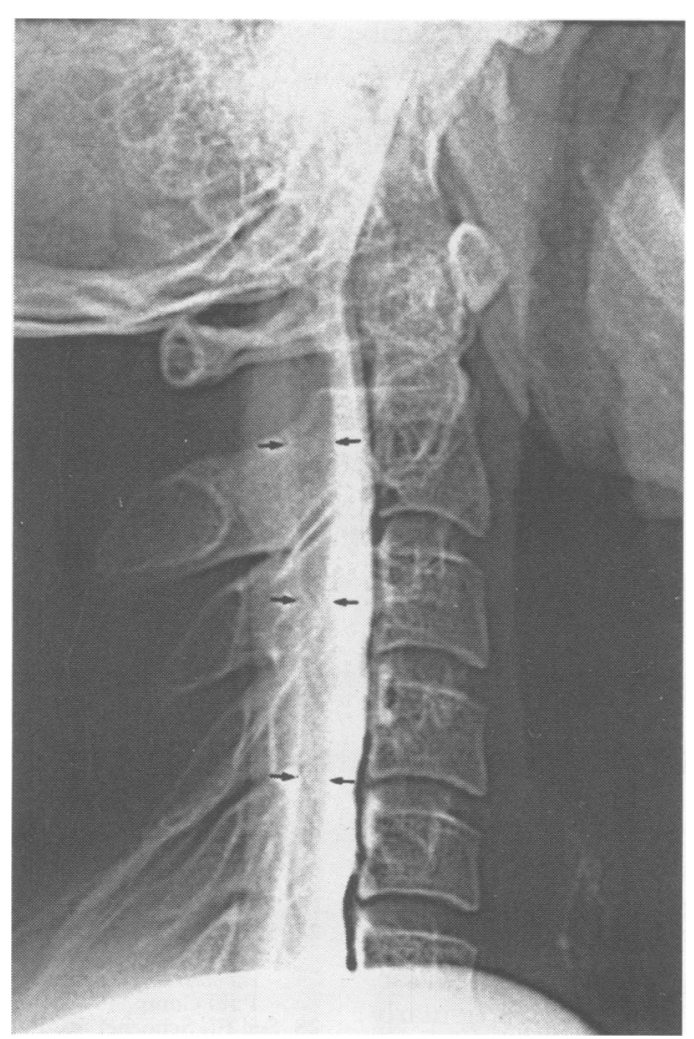

Figure 4 Cervical myelogram showing atrophy of the whole of the cervical cord from the foramen magnum to C6. (Patient III.6). ring daily and lasting approximately half an hour. These attacks persisted and six years later she became aware of heaviness of the left leg which limited her ability to walk more than 100 yards. She also complained of poor balance, a recent change in the quality of her speech and urgency of micturition. Cognitive functions were normal. On examination her gait was unsteady and she dragged the left leg. Her voice was nasal in quality. The optic discs were normal and the eye movements were full with no nystagmus although the pursuit movements were jerky. Voluntary palatal movements were weak with no myoclonus; tongue movements were normal. There was mild bilateral limb ataxia with pyramidal weakness of the left leg and an extensor plantar response on that side. MRI scan showed scattered white matter lesions with atrophy of the brainstem.

\section{Discussion}

The patients described have a variable syndrome comprising progressive branchial myoclonus, bulbar weakness, nystagmus and spastic tetraparesis. Inheritance is probably autosomal dominant. Although an autosomal recessive disorder with a pseudodominant pattern due to consanguinity cannot be excluded, the absence of consanguinity between II.1 and II.2 makes this relatively unlikely. The clinical presentation suggested several possible diagnoses including mitochondrial encephalomyopathy, multisystem atrophy associated with branchial myoclonus and non-familial degenerative disorders. The neurological history in all three cases and the asymmetrical physical signs in case III.5, was compatible with demyelinating disease. Although multiple sclerosis may be familial, ${ }^{16}$ its occurrence in seven members of a native Kuwaiti family would be unusual. Furthermore, the CSF and VEP studies were normal and whilst the MRI scan showed evidence of high signal, the appearance of the brainstem lesion was not suggestive of demyelination.

Leigh's subacute necrotising encephalomyelopathy is a heterogenous syndrome characterised by defects of the mitochondrial respiratory chain in some cases. ${ }^{1718}$ The diagnosis was considered in the present cases because of the presence of brainstem lesions, extensive MRI changes, and muscle biopsy suggesting denervation. However, there was no evidence of visual impairment, dystonia, psychiatric disturbance or epileptic seizures, nor were there ragged red fibres on the muscle biopsy; furthermore discrete pontine lesions are not a feature of Leigh's disease. ${ }^{19} 20$

Patient III.6 had frequent episodes of limb paralysis associated with sneezing. These were not witnessed and the aetiology remains uncertain, but transient episodes of atonia precipitated by trigger factors such as laughter, intense emotion or sneezing are suggestive of cataplexy. Secondary cataplexy is rare ${ }^{21}$ but has been described in association with lesions involving the rostral midbrain, ${ }^{22}$ 
prechiasmatic hypothalamus ${ }^{23}$ and in Niemann-Pick disease. ${ }^{24}$

The presence of Rosenthal fibres raised the possibility of Alexander's disease. This is usually a sporadic leukodystrophy of unknown aetiology which presents in infancy and is characterised clinically by progressive macrocephaly, failure to thrive, psychomotor retardation, spasticity, and epilepsy culminating in death within months or years. ${ }^{2526}$ Pathologically there is extensive demyelination and the presence of Rosenthal fibres. ${ }^{27}$ The later onset forms of Alexander's disease are much less clearly defined, ${ }^{11}$ being restricted to a small number of patients with heterogeneous clinical features consistent with classic multiple sclerosis ${ }^{28}$ but with Rosenthal fibre formation. Herndon et al ${ }^{10}$ suggested that these patients did indeed have multiple sclerosis associated with an abnormality of astroglia leading to the formation of Rosenthal fibres, but a number of cases remain in which the distinctive clinical features suggest Alexander's disease. ${ }^{28-31}$ Although the possible familial occurrence of infantile onset Alexander's disease has occasionally been reported, ${ }^{32-35}$ there have been no reports of familial cases of the adult form. A number of features in the present family may be compatible with the ill defined entity of adult onset Alexander's disease. These include the development of a spastic paraparesis with the presence of Rosenthal fibres. However, the progression in our case was slow and there was no intellectual deterioration or seizures. Furthermore there was marked brainstem involvement with bulbar palsy, palatal myoclonus and extensive discrete lesions in the pons on MRI with a clear family history. Thus despite the pathological findings, the diagnosis of adult onset Alexander's disease seems inappropriate.

de Yebenes et $a l^{7}$ described a family with an autosomal dominant syndrome characterised by branchial myoclonus as the initial manifestation associated with the development of spastic paraparesis and cerebellar ataxia. There were 6 affected individuals in 2 generations who presented in the fourth and fifth decades with palatal myoclonus and bulbar weakness, occasionally requiring tracheostomy and feeding gastrotomy. There was subsequent spastic paraparesis and cerebellar ataxia. CT scans showed predominant subcortical atrophy with periventricular areas of low density and cerebellar atrophy. MRI showed ventricular dilatation, mild atrophy of the corpus callosum and marked atrophy of the cerebellum, medulla and cervical spinal cord with high signal in the periventricular region and the putamen. Our family also presented with branchial myoclonus and progressive bulbar weakness, spastic paraparesis and cerebellar degeneration. The onset was at a younger age than the family described by de Yebenes $^{7}$ but the progression was similar. The MRI features were different, particularly in case III. 7 with a large discrete lesion in the pons, as well as abnormal signal and marked atrophy of the brainstem and cervical cord.
No pathological data were described in the previous report. The disorder observed in the present family may represent either a variant of the disorder described by de Yebenes or a distinct, hitherto unrecognised syndrome.

1 Deuschl G, Miscchke G, Schenck E, Schulte Monting J, Lucking $\mathrm{CH}$. Symptomatic and essential rhythmic myoclonus. Brain 1990;113:1645-72.

2 Masucci EF, Kurtzke JF, Saini N. Myorhythmia: a widespread movement disorder. Clinicopathological widespread movement disorder.

3 Jankovic J, Pardo R. Segmental myoclonus. Arch Neurol 1986;43:1025-31.

4 Nagaoka $M$, Narabayashi $H$. Palatal myoclonus-its remote influences. $\mathcal{F}$ Neurol Neurosurg Psychiatry 1984; 47:921-6.

5 Sperling MG, Herrmann C. Syndrome of palatal myoclonus and progressive ataxia: Two cases with magnetic resonance imaging. Neurology 1985;35:1212-4.

6 Leger JM, Ducckaerts C, Brunet P. Syndrome of palatal myoclonus and progressive ataxia: report of a case. Neurology 1986;36:1409-10.

7 de Yebenes JG, Vazquez A, Rabano J, et al. Hereditary branchial myoclonus with spastic paraparesis and cerebellar ataxia: a new autosomal dominant disorder Neurology 1988;38:569-72.

8 Rosenthal W. Uber eine eigentiumliche, mit Syringomyelie komplizierte Geschwulst des Ruckenmarks Beitrage zur Pathologische Anatomie und zur Allgemeinen Pathologie 1898;23:111-43.

9 Alexander WS. Progressive fibrinoid degeneration of fibrillary astrocytes associated with mental retardation in a hydrocephalic infant. Brain 1949;72:373-81.

10 Herndon RM, Rubinstein LJ, Freeman JM, Mathieson G. Light and electron microscopic observations on Rosenthal fibres in Alexander's disease and in multiple sclerosis. $\mathcal{f}$ Neuropathol Exp Neurol 1970;29:524-50.

11 Borrett D, Becker LE. Alexander's disease-a disease of astrocytes. Brain 1985;108:367-85.

12 Soffer D, Horoupian DS. Rosenthal fibre formation in the central nervous system-its relation to Alexander's disease. Acta Neuropath 1979;47:81-4.

13 Gluszcz A. Disseminate cerebral gliomatosis with fibrillary degeneration of the glia and with Rosenthal fibres. Acta Neuropath 1964;4:212-7.

14 Mastri AR, Sung JH. Diffuse Rosenthal fibre formation in the adult: A report of four cases. $\mathcal{F}$ Neuropath Exp Neurol 1973;32:424-36.

15 Tihen WS. Central pontine myelinolysis and Rosenthal fibres of the brainstem-association with emaciation and prolonged intravenous hyperalimentation. Neurology 1972;22:710-6.

16 Myrianthopoulos NC. Genetic aspects of multiple sclerosis. In Koetsier JC ed. Handbook of clinical neurology. sis. In Koetsier JC ed. Handbook of clinical

17 New York: Elsevier, 1985;3 (47):289-317. ${ }^{2}$ Mitochondrial cytopathy or Leigh's syndrome? Mitochondrial abnormalities in spongiform encephalopathies. Neuropaed 1982;13:219-24.

18 Lake BD, Harding BN. Leigh's disease-a morphological appearance or a biochemical abnormality? A report of a case in a 4 day old infant with muscle cytochrome oxidase deficiency. Paed Pathol 1987;7:131-2.

19 Gray F, Louarn F, Gherardi R, Eizenbaum JF, Mersault C. Adult form of Leigh's disease: A clinicopathological case with CT scan examination 7 Neurol Neurosurg Psychiatry 1984;47:1211-5.

20 Marsden CD, Lang AE, Quinn NP, McDonald WI, Abdallat A, Nimri S. Familial dystonia and visual failure with striatal CT lucencies. $¥$ Neurol Neurosurg Psychiatry with striatal CT

21 Parkes D. Sleep and its disorders. London: W B Saunders, 279-81.

22 Stahl SM, Layzer RB, Aminoff MJ, Towsend JJ, Feldon $\mathrm{S}$. Continuous cataplexy in a patient with a midbrain tumour: the limp man syndrome. Neurology 1980;30: 1115-8.

23 Schwartz WJ, Stakes JW, Hobson JA. Transient cataplexy after removal of a craniopharyngioma. Neurology 1984;34:1372-5.

24 Kandt RS, Emerson RG, Singer HS, Valle DL, Moser HW. Cataplexy in variant forms of Niemann-Pick disease. Ann Neurol 1982;12:284-8.

25 Russo LS, Aaron A, Anderson PJ. Alexander's disease: A report and reappraisal. Neurology 1976;26:607-14.

26 Holland IM, Kendall BE. Computed tomography in Alexander's disease. Neuroradiology 1980;20:103-6.

27 Stam FC. Megalencephalic type of congenital leucodystrophy. In: Vinken PJ, Bruyn GW, ed. Handbook of clinical neurology, volume 10 . Amsterdam: North Holland, cal neurology, volum

28 Seil FJ, Schochet SS, Earle KM. Alexander's disease in an adult: Report of a case. Arch Neurol 1968;19:494-502.

29 Vogel FS, Hallervordan J. Leucodystrophy with diffuse Rosenthal fibre formation. Acta Neuropath 1962;2: 126-43. 
30 Stevenson LD. Discussion of: cases of unusual, presumably familial leucodystrophy in megalencephaly. f Neuropath Exp Neurol 1957;16:129-30.

31 Walls TJ, Jones RA, Cartlidge NEF, Saunders M Alexander's disease with Rosenthal fibre formation in an adult. $\mathcal{F}$ Neurol Neurosurg Psychiatry 1984;47: .399-403.

32 Barbieri F, Filla A, De Falco FA, Buscaino GA. Alexander's disease. A clinical study with computerized tomographic scans of the first two Italian cases. Acta Neurol 1980;35:1-9.
33 Wohlwill FJ, Berstein J, Yakovlev PI. Dysmyeliogenic eucodystrophy. Report of a case of a new, presumably, familial type of leukodystrophy with megalobaren cephaly. I Neuropath Exp Neurol 1959;18:359-83.

34 Schochet SS, Lampert PW, Earle KM. Alexander's disease: A case report with electron microscopic observations. Neurology 1968;18:543-9.

35 Garret R, Ames RP. Alexander's disease. Case report with electron microscopal studies and review of the literature. Arch Pathol 1974;98:379-85. 